\title{
THE LOGISTIC OF EMPTY CONTAINERS' RETURN IN THE LINER-SHIPPING NETWORK
}

\author{
Naima Belayachi ${ }^{1}$, Shahin Gelareh ${ }^{2}$, Khadidja Yachba $^{3}$, Karim Bouamrane $^{4}$ \\ ${ }^{1,3,4}$ Department of computer science, University of Oran1 Ahmed Ben Bella, \\ BP 1524El M'nouer, Oran, Algeria, \\ Ph.: ${ }^{1}+213773753114,{ }^{3}+213778281905,{ }^{4}+213666442474$

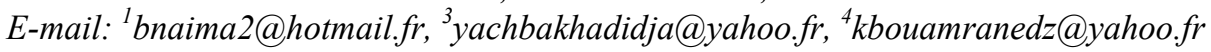 \\ ${ }^{2}$ University of Portsmouth, Portsmouth, Hampshire, \\ PO13DE, United Kingdom \\ E-mail:shahin.gelareh@gmail.com
}

\begin{abstract}
The Maritime Transport is a favoured tool regarding the universal exchanges because it has gone through several evolutions. Indeed, the containerization is considered as one of the most remarkable improvements in the shipping. The containers are rented by shipping companies. However, these companies meet an empty container availability problem at some ports of Maritime Transport Network (MTN) to satisfy the demands of clients. The objective of this work is to solve the problem of the imbalance of the distribution of containers and look for empty containers at less cost to meet the demands of clients. As a result, the authors propose an application to represent the MTN, and provide a balanced distribution of containers. The work presented in this article is based on a heuristic method by neighbourhood. It allows the process of the clients' demands and transfers of full containers as well as the research of empty containers by optimizing the cost of theirs return.
\end{abstract}

Keywords: Maritime Transport Network (MTN), empty container, client' demand, optimization, Taboo Search

\section{Introduction}

The contribution of the authors is a part of reverse logistics in the field of Maritime Transport. The Maritime Transport is a preferred mechanism for international trade, which is facing a strong competition from the railway and the road. This mode of transport has gone through many revolutions and it has undergone several changes and improvements in order to adapt to merchandise exchanges between nations.

More precisely, the researchers are interested in the problems related to the management of full containers as well as the repositioning of empty containers, which represents the return flow in the reverse logistics in this work.

The reverse logistics concerns the management of the flow of products that returned from the client to the manufacturer. Sometimes, the consumer is not satisfied with the delivered product, so he decides to return it to the producer. This represents the flow of reverse logistics, when the consumer returns the product to the distribution centre, then the distribution centre returns the product to the aftersales service for being reset in a new state, recycling. Otherwise, the product can be rejected.

In this study, the chain of reverse logistics is considered as the return of empty containers from one port to another to respond to a client demands.

The paper is organized as follows: Section 2, is dedicated to the presentation of a state of art. In Section 3, the authors outline the problem being addressed. Section 4, is dedicated to a detailed presentation of the contribution, and followed by a discussion of the results in Section 5. The researchers conclude this paper by a synthesis in section 6, and a conclusion with some perspectives in Section 7.

\section{State of Art}

In order to point out everything that is connected to the present work, a state of art was done to get closer to this axis of research, which has naturally led researchers to focus on and to propose adequate models.

A discrete-time linear analytical model was proposed in (Hu et al., 2002) to solve a minimization problem of the costs of reverse logistics for the treatment of hazardous waste. Another model was 
proposed by (Min et al., 2006), who use genetic algorithms to study the problem of management of returned products. Also, (Yachba et al., 2016) use the genetic algorithms to optimize the storage space of dangerous containers in the maritime sector and minimize unnecessary movements. For the design of a reverse logistics network, a mathematical model of linear programming was proposed in (Zhou and Wang, 2008), where the objective function of the model is to minimize the total cost of the system for the management of returned products. On another side, (Srivastava, 2008) provided a design of a reverse logistics network, and he offered a three-level design (products returned by clients, collection's centres, factories). He considered that the client is the source of the returned products. The proposed objective function is to maximize the profit, which is equal to revenues minus the sum of resales cost of reverse logistics and the price of resolution.

Besides, (Lee et al., 2009) offered a work that addressed a problem of reverse logistics process for a remanufacturing of returned products. This problem is one of the most important problems in the environment of the recovery of the used products. The proposed model focused on minimizing the total cost of reverse logistics using genetic algorithms combined with a method based on priority and heuristics. Still in the context of reverse logistics, (Mutha and Pokharel, 2009) presented a strategy for the design of a reverse logistics network and re-manufacturing using new or old product modules. The returned products must be consolidated in the warehouse before being sent to recycling centres for inspection and removal another important part. The disassembled parts are sent to re-manufacture or to the secondary market as spare parts. The objective function consists of minimizing the cost of transportation, inventory, disposal of unused parts and assembly cost. In 2012, (Alumur et al., 2012) proposed a linear programming for a reverse logistics network design. The objective function maximizes the gain that is equal to the sum of profit from recycling centres, manufacturing plants, and the secondary market minus the fixed costs of establishing of operating and transportation facilities, storage, and purchasing components. The model is applied to washing and dryers machines that are collected from 40 collection's centres in the 40 most populated cities in Germany. Ramezani et al. in (2013), presented a multi-objective stochastic model for direct / reverse logistics network design in an uncertain environment, with three steps in the forward direction (suppliers, factories, distribution centres) and two levels in the backward direction (the collection centres and storage ones).

Reverse logistics is a domain that has a magnitude in recent years. It is a system of management of the returned products by the client and recovered by the company, which includes shares of recycling, dismantling, and remanufacturing, for the recovery of client products. In the domain of Maritime Transport, this discipline does not attract the attention of researchers. Several works can be found but they concerned the direct logistics that is easy to manage compared to the uncertainty of reverse logistics. Furthermore, the authors of this paper will also overfly some studies that address the optimization problem in the Maritime Transport sector. Crainic in (2000) proposed a model of a shipping network as a graph containing nodes connected by links, which are directed and represented as arcs in the network. Some nodes are the origins of the transport demand for one or more products, and others represent the destinations of this traffic. The links can have various characteristics, such as length, capacity, and cost. The objective is to select links in a network with capacity to meet transport demand at the lowest cost possible. A mixed integer programming was proposed by Gelareh et al. (2010) for the design of hub-andspoke networks in a competitive environment. This work treats the competition between a new provider lines and a dominant existing operator, working both of them on the hub-and-spoke networks. The new company maximizes its market share, which depends on the length of service and transport costs by locating a predetermined number of hubs in the candidate ports and established the design of its network. A method of Lagrange accelerated combined with a primal heuristic has been proposed. Another work of (Gelareh and Qiang, 2010) focused on the development of model for the problem of the fleet deployment for short-term Maritime Transport operations. The work proposes a mixed linear programming model to determine the optimal frequency of the service line and takes into account the time constraints of shipping services. More recently, Shuaian et al. (2013) proposed a mathematical model to generate paths containers while taking into account operational constraints. At first, they gave a representation of the Marine Transportation Network then; they proposed a linear programming model based on the operational network whose goal is to get all the paths of the containers for each pair origin-destination with a minimum cost. Finally, they added constraints to the linear programming model, excluding the paths already obtained to find all container paths. Additionally, the authors cite the work of (Gelareh et al., 2013) which offered a mixed linear programming model for the design of Marine Transportation Network, and an allocation of ships depending on the size of the chain (all the shipping companies divide 
their service regions into several chains composed of an ordered set of ports) in order to ensure a good adjustment of the operating frequency at each chain. They proposed a Lagrangian decomposition approach that uses a heuristic procedure, which can achieve practical solutions and high quality in a reasonable time. Similarly, the problem of the empty containers repositioning in the maritime networks under possible disturbances is found in the work of (Francesco et al., 2013). They consider data uncertainty related to this problem by a stochastic programming approach, where different scenarios are included in a multi-scenario optimization model. The work of (Song and Dong, 2013) proposed a design for a maritime service line of long distance taking into account the road structure, deployment of ships, and the repositioning of empty containers. The objective is to minimize the total cost of the charges of a shipping service line of long distance, including costs related to the ship, fuel consumption costs, port costs, transfer cost and the storage of full and empty containers. Regarding the problem of empty containers repositioning, they proposed an algorithm to minimize the loading and unloading movements of these latter.

Table 1. Comparative study

\begin{tabular}{|c|c|c|c|c|c|c|c|c|c|}
\hline 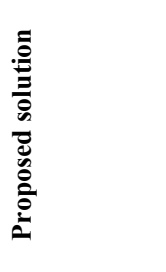 & 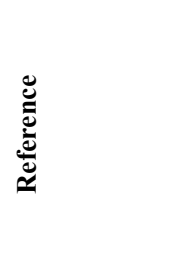 & 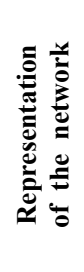 & & 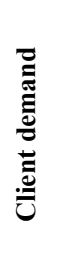 & 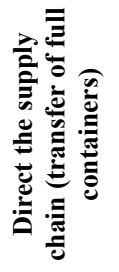 & 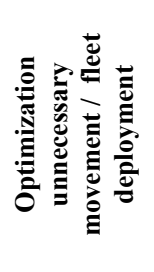 & 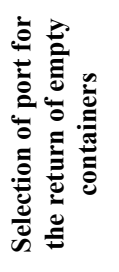 & 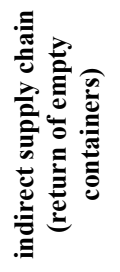 & 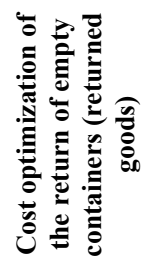 \\
\hline \multirow[t]{9}{*}{$\begin{array}{l}\text { Mathematic } \\
\text { model }\end{array}$} & $\begin{array}{l}\text { (Hu et al., } \\
2002)\end{array}$ & & & & & & & $\mathrm{X}$ & $X$ \\
\hline & $\begin{array}{l}\text { (Zhou and } \\
\text { Wang, 2008) }\end{array}$ & $X$ & & & & & & $\mathrm{X}$ & $X$ \\
\hline & $\begin{array}{l}\text { (Srivastava, } \\
2008 \text { ) }\end{array}$ & $X$ & & & & & & $X$ & $X$ \\
\hline & $\begin{array}{l}\text { (Mutha and } \\
\text { Pokharel, } \\
\text { 2009) }\end{array}$ & $X$ & & & & & & $X$ & \\
\hline & $\begin{array}{l}\text { (Alumur et } \\
\text { al., 2012) }\end{array}$ & $X$ & & & & $\mathrm{X}$ & & $\mathrm{X}$ & $X$ \\
\hline & $\begin{array}{l}\text { (Gelareh and } \\
\text { Qiang, } \\
2010 \text { ) }\end{array}$ & $X$ & & & $X$ & $X$ & & & \\
\hline & $\begin{array}{l}\text { (Gelareh et al., } \\
\text { 2010) }\end{array}$ & $X$ & & & & $X$ & & & \\
\hline & $\begin{array}{l}\text { (Shuaian et al., } \\
\text { 2013) }\end{array}$ & $X$ & & & $X$ & & & & \\
\hline & $\begin{array}{l}\text { (Gelareh et al. } \\
\text { 2013) }\end{array}$ & $X$ & & & $X$ & $X$ & & & \\
\hline \multirow[t]{2}{*}{$\begin{array}{l}\text { Stochastic } \\
\text { model }\end{array}$} & $\begin{array}{l}\text { (Ramezani et } \\
\text { al., 2013) }\end{array}$ & $X$ & $\mathrm{X}$ & & $\mathrm{X}$ & & & $X$ & $X$ \\
\hline & $\begin{array}{l}\text { (Francesco et } \\
\text { al., 2013) }\end{array}$ & $X$ & $X$ & & & & & $X$ & $X$ \\
\hline \multirow[t]{3}{*}{$\begin{array}{l}\text { Genetic } \\
\text { Algorithm }\end{array}$} & $\begin{array}{l}\text { (Min et al., } \\
\text { 2006) }\end{array}$ & & & & & & & $X$ & $X$ \\
\hline & $\begin{array}{l}\text { (Lee et al., } \\
2009 \text { ) }\end{array}$ & $X$ & & & & & & $X$ & $X$ \\
\hline & $\begin{array}{l}\text { (Yachba et al., } \\
\text { 2016) }\end{array}$ & & & & & $X$ & & & \\
\hline $\begin{array}{l}\text { Algorithm to } \\
\text { minimize } \\
\text { unnecessary } \\
\text { movement of } \\
\text { empty } \\
\text { containers }\end{array}$ & $\begin{array}{l}\text { (Song and } \\
\text { Dong, 2013) }\end{array}$ & $X$ & & & & $X$ & & & $X$ \\
\hline $\begin{array}{l}\text { Graph of } \\
\text { vertices }\end{array}$ & $\begin{array}{l}\text { (Crainic, } \\
2000)\end{array}$ & $X$ & & $X$ & $X$ & & & & \\
\hline
\end{tabular}


Maritime Transport represents crucial preoccupation. In addition, different companies provide great efforts in order to identify opportunities to reduce costs associated with this transport. However, to be competitive, Maritime Transport must improve its services and reduce the costs. Therefore, several questions are required: How to do in order to: ensure a better tracking of goods? minimize delays? increase the storage capacity?, optimize the return's cost of empty containers, which represent the interest of this work. All these questions arise in the different activities carried in each port. This has encouraged the authors to propose a model based on a heuristic method to search for empty containers with a minimal cost while ensuring a balanced distribution of containers in RTM.

The authors are interested in works that are related to reverse logistics and empty containers. For this reason, a comparative study between the works presented above was made, where different criteria have been taken into account as shown in the Table 1.

\section{Positioning of the Problem}

The objective of this work is to propose a tool to represent the Marine Transportation Network and to ensure a balanced distribution of the containers between the ports to satisfy the clients and maximize the efficiency and profitability of the MTN's lines by optimising the cost of empty containers' return, which is on the charge of the owners of these containers. Container ship owners seek above all to ensure the filling of ships with full containers, regardless of the type of goods. They try to balance the number of containers transported in forward and the return between ports. However, unfortunately, the imbalance of trade balances of countries affects the containerized trade. Some countries produce more than others, and some countries import more goods they export. This affects the flow of containers transported by seaway, which will be imbalanced. For this purpose, the containers' owners are confronted with two major problems: a difficulty achieving a balanced flow of containers and a profitability of the lines, which degrades. In other words, the number of containers exported from the port $p$ to another port $p^{\prime}$ is greater than the number of imported containers in the port $p$. This does not respect the conservation of the container's flows between the ports of the Marine Transportation Network. Therefore, an imbalance occurs in container's distribution. In this situation, when a client's demand comes at a port that has not enough empty containers in its stock, then this demand will not be treated or the owner will try to find empty containers in an arbitrary manner. However, sometimes at a high cost that the owner must pay causes a lowering of the efficiency of the MTN's lines.

In this paper, a resolution of the problem described above is proposed. The model allows to visualize the treatment of the clients' demands from the origin to the destination, and the research for empty containers at lower cost if a port does not find empty containers available at its stock to take charge the demand, in such a way to keep the balance in the distribution of the containers on the Marine Transportation Network.

\section{Contribution}

The contribution presented in this paper, is responsible for the management of the clients' demands regarding the arrivals and departures of containers in the port, also it allows the optimization of the return's cost of the empty containers at the moment of searching of these later. The research of the empty containers is based on a heuristic method by neighbourhood.

Specifically, in this work, the authors study the return of the empty containers transported on a shipping line, to keep a balance in terms of import and export containers at ports. To remedy this problem, the authors have used a heuristic method by neighbourhood. Additionally, the principle of this method is to go through all the possible solutions from an initial solution (The port that does not find available empty containers will choose a port in its neighbourhood as an initial solution to look for empty containers) and moving to other neighbours step by step.

This study takes place as a part of reverse logistics, where the containers returned from a port p1 to a port p2 represent the products that are returned from the client to the manufacturer in the chain of reverse logistics (Belayachi et al., 2015). The present contribution is a help for the containers' owner. It represents the reverse logistics chain regarding the return of the empty containers in the MTN in order to ensure their availability and satisfy the client's demands and send the goods. Figure 1 allows to schematize the general operating process of this proposal. 


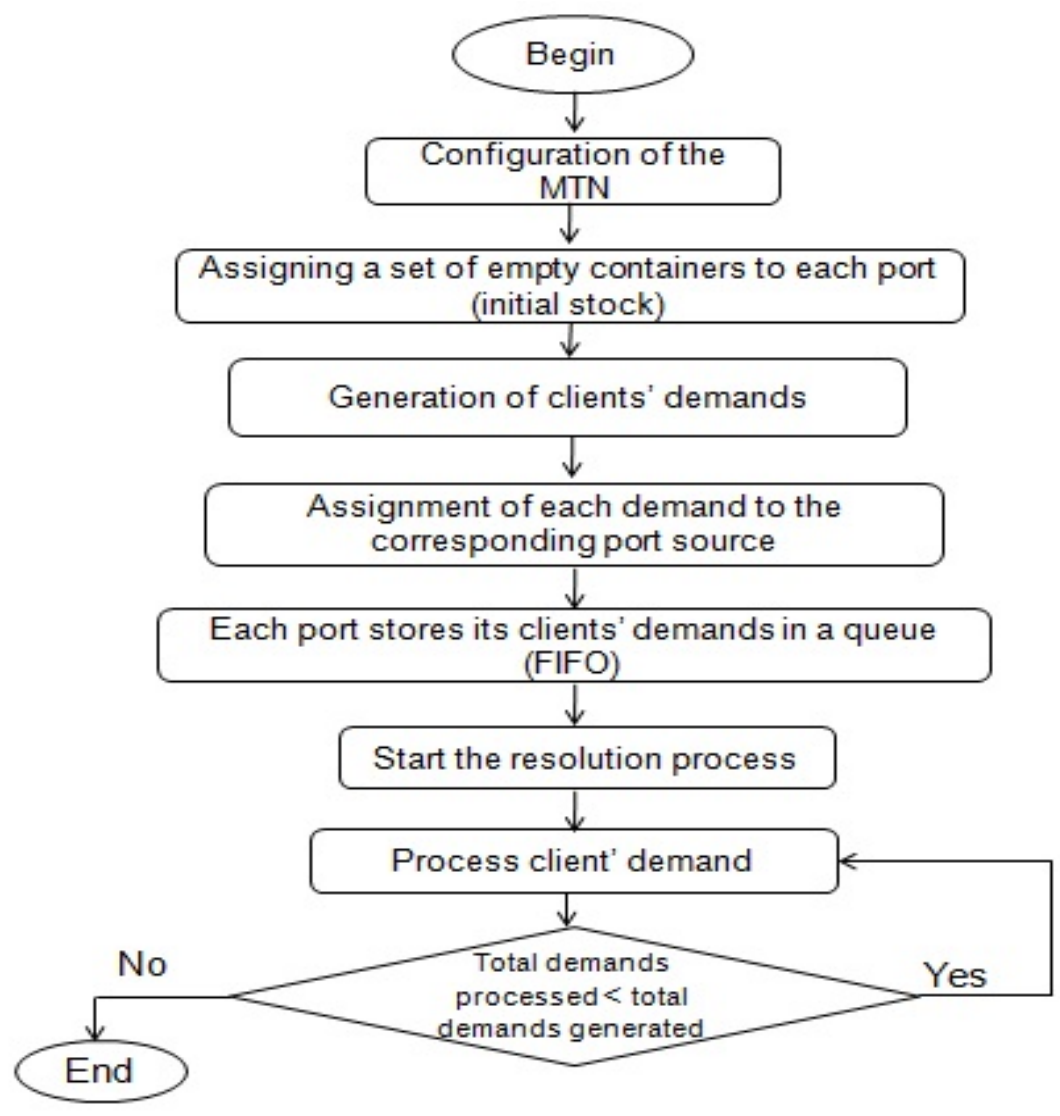

Figure 1. Functional architecture of the proposed application

\subsection{Representation of the Marine Transportation Network (MTN)}

By inspiring from the works of (Francesco et al., 2013) and (Meng et al., 2012) that have modelled the Marine Transportation System by a graph of vertices, the authors of this paper propose a representation of the MTN by a graph composed of a set of nodes symbolizing the ports of the network, which are connected by edges according to the network lines. The ports belong to the same line form a neighbourhood (Fig. 2), where:

- The network is composed of a set of ports.

- Ports are connected via lines.

- Each port knows its neighbours.

- Each port has a queue to store client demands. The queue is managed in a FIFO (First In First Out) manner.

- A certain number of empty containers is assigned to each port (initially).

- A container transfer cost is attributed to both cases (empty / full) between each pair of ports (origin, destination).

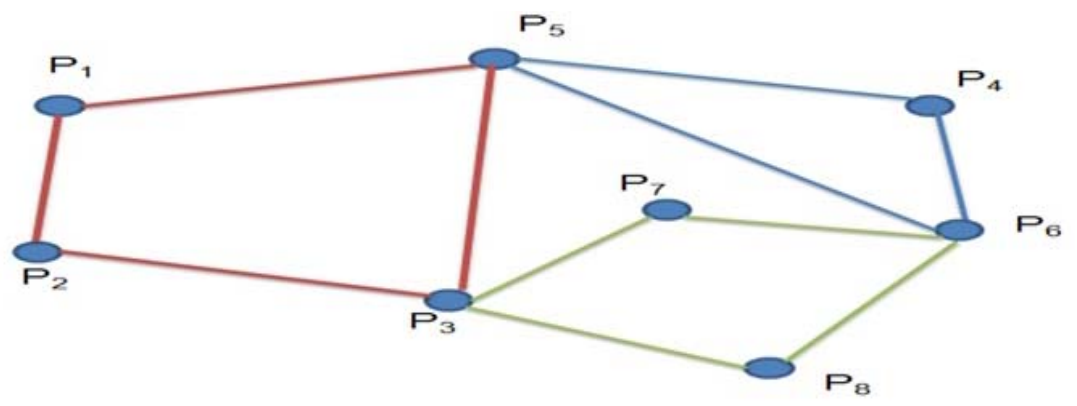

Figure 2. Maritime Transportation Network representation 
The representation of the RTM is the support used by Taboo Search for any solution of the neighbourhood (ports in the same neighbourhood).

After introducing the representation of the RTM, the authors move to the generation of the clients' demands. Each demand is characterized by a source port, destination port, a number $n \_$exp of empty containers, which are needed to transport the goods, and a state to know if the demand is placed on hold in the source port queue, or it is processed with or without Taboo Search. In addition, a cost is calculated for each client demand to transport the goods through the containers.

Once the generation of demands is completed, the authors launch the processing of the clients' demands that it ends when all the generated demands will be processed. Accordingly, an explanation of the management of the clients' demands, and the transfer of containers will be given.

\subsection{Clients' demands treatment process}

When a port receives a client demand that needs empty containers to send merchandise, this will export a number $n \_$exp of containers. In this situation, two cases are possible (Fig. 3):

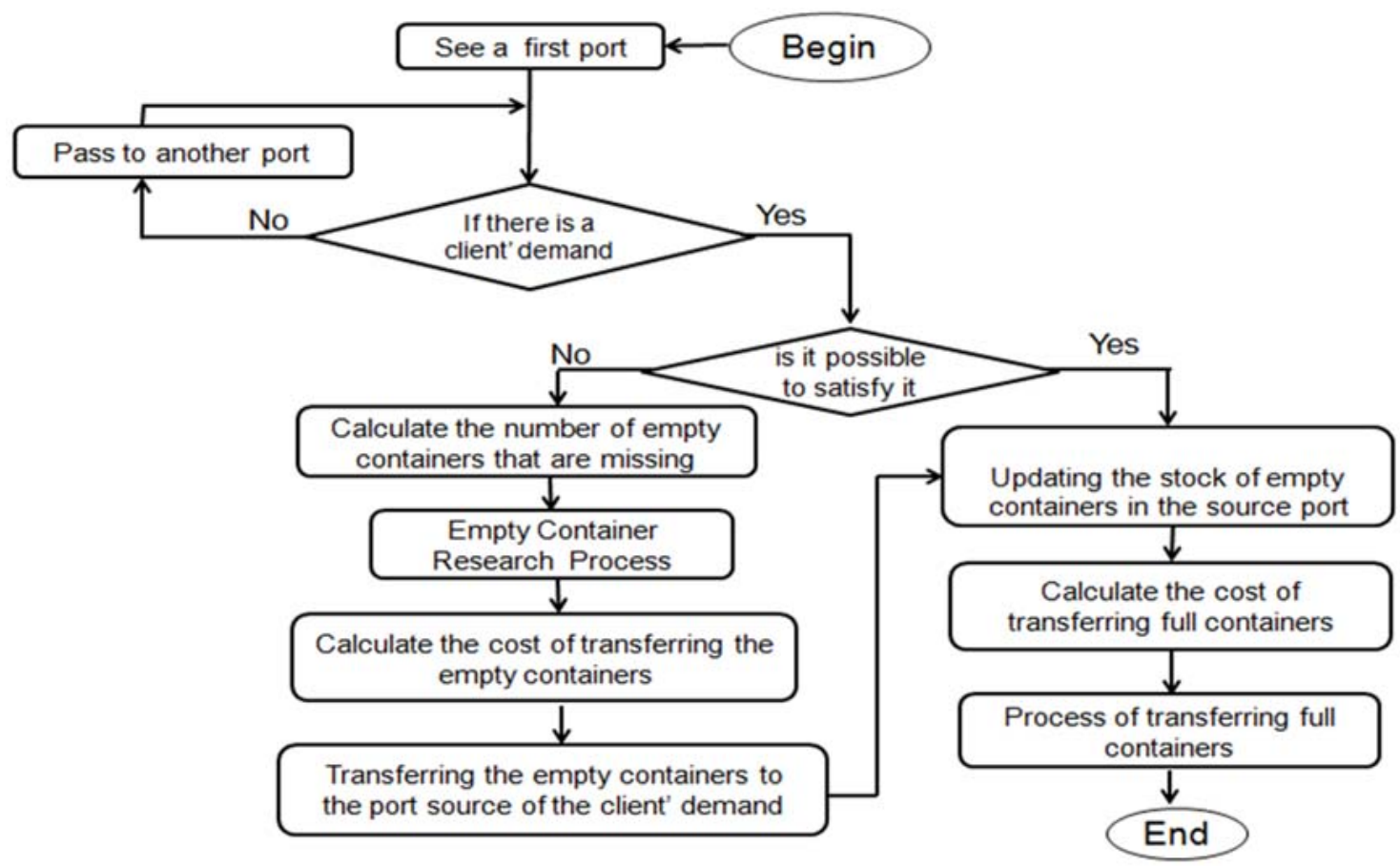

Figure 3. Treatment process of a client demand

Case 1: stock of port $p \geq n \_$exp, so there is no problem in this case. The containers will be filled and sent to the destination by updating the stock of source port and destination port once the containers arrive at destination of the demand.

Case 2: stock of port $p<n \_\exp$, in this second case, the number of containers to export, which are greater than the number of empty containers available at the stock of port $p$ (source port of the client's demand). This implies that the port cannot meet the demand and send all containers demanded by its client. In this case, the authors apply the Taboo Search's method to allow the port to look for $n b \_c o n t$ empty containers that are available at the ports of their neighbourhood at a minimum cost to respond positively to the client's demand ( $n b \_c o n t=n \_$exp - Stock of port $\left.p\right)$.

The authors recall that a neighbourhood of a port belonging to a line $l$ is composed of all ports that belong to the same line of the MTN. Figure 4 illustrates the principle of Taboo Search which is applied to the situation described before. 


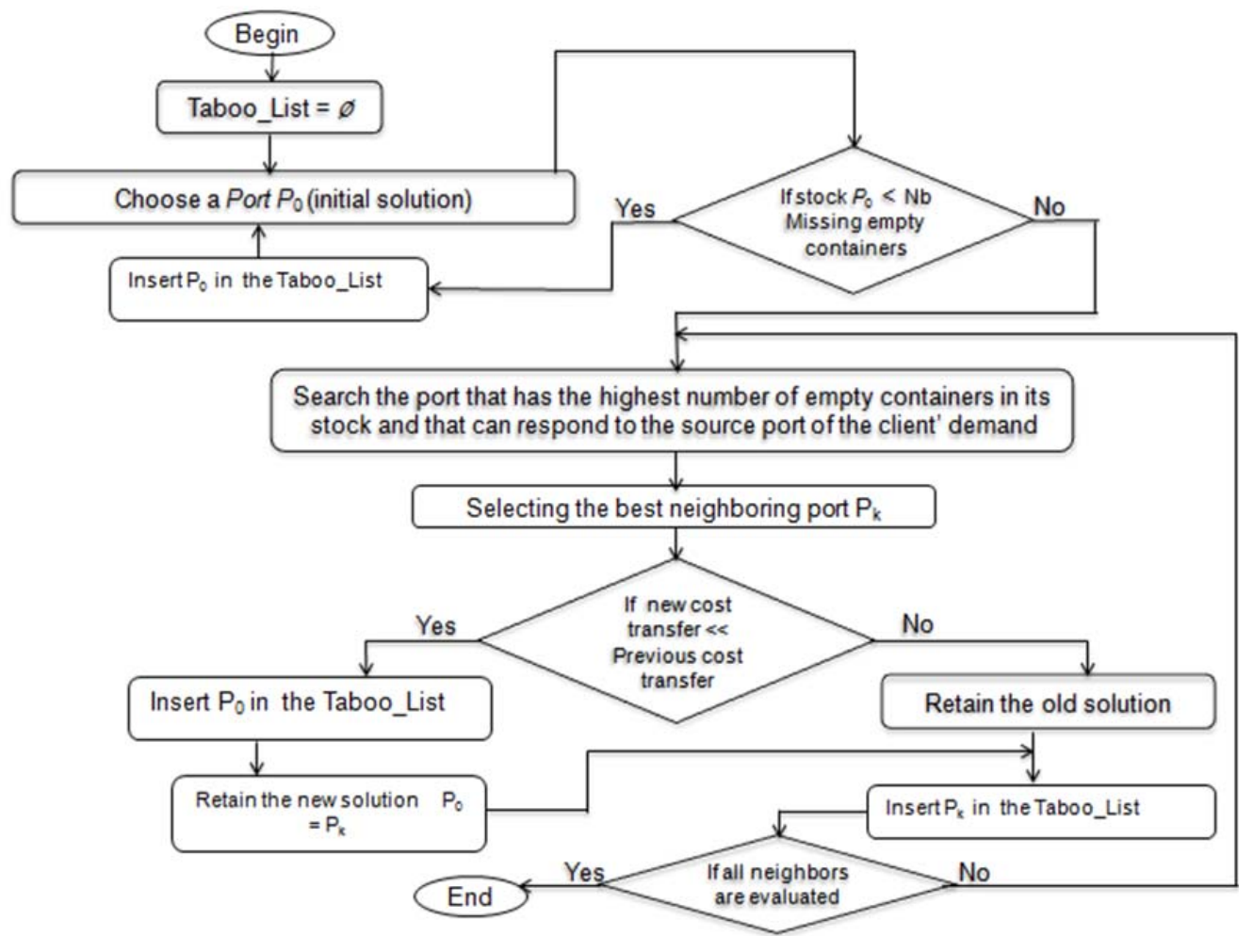

Figure 4. Principle of the applied research method

The following algorithm (Fig. 5) helps to explain the search of empty containers when a client demand comes at a source port $p_{s}$ and requires a number of empty containers $n b_{-}$cont that are not available in $p_{s}$.

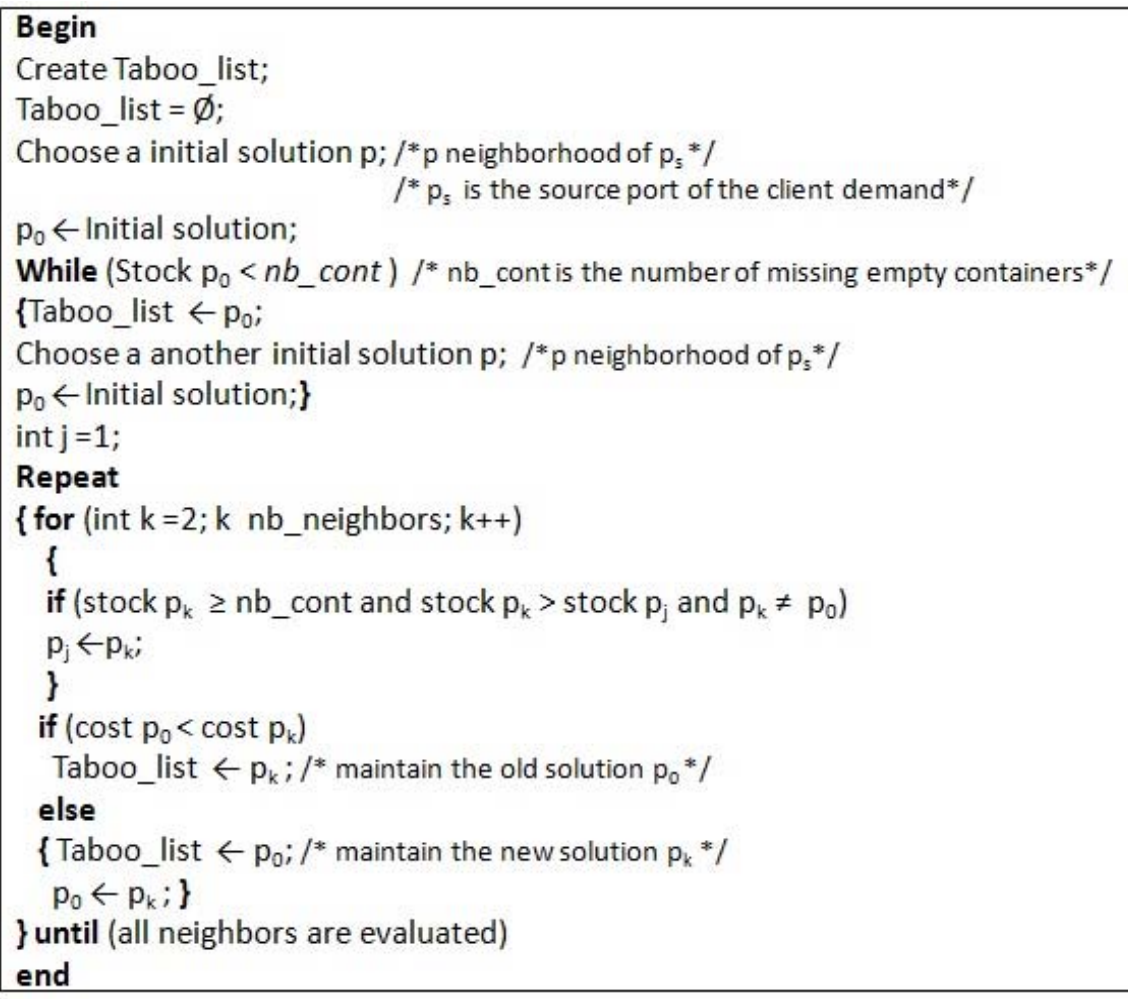

Figure 5. Algorithm of empty containers' search 
Once the Taboo Search is over, the neighbour port which is selected to send empty containers at a lower cost, will send the required number of empty containers to the source port of the client's demand at a cost (cost with TS, which represents the objective function) calculated according to the distance between each port pair for transferring the missing empty containers (1). The containers' owner in the source port $p_{s}$ must pay this amount and satisfy its client's demand.

In other words, a mathematical formulation can be given, in order to optimize the cost of empty containers' return, as follows:

$C_{k s}=P u *$ dist $_{k s} * n b_{-}$cont $_{s}$,

- $C_{k s}$ : The cost of transportation of empty containers, that are returned from a port $P_{k}$ to the requesting port $P_{s}$.

- $\quad P u$ : The unit price for transportation of one empty container.

- dist $_{k s}$ : The distance between the requesting port $P_{s}$ and the sender port $P_{k}$.

- $n b \_$cont $t_{s}$ The number of missing empty containers, to be transported to the port $P_{s}$.

The cost of transporting the empty containers returned to a requesting port must be as minimal as possible because this cost is on the charge the owner of those containers, unlike to the "client cost" that the client must pay to transport the full containers in order to send his goods.

In the present study, the researchers suppose that a transaction of empty containers' research cannot be made without a demand from a client to meet a shipment of his goods from a source port to a destination port, and by admitting that these containers are of the same type, they followed some constraints:

- Availability constraint: When searching for a neighbouring port, the proposed work look for the port that has the most empty containers available in order to keep a balanced distribution on the network but with the controlling of the return's cost if it is not fairly high compared to the return's cost from another port that has less empty containers in its stock. If a quantity of empty containers requested is not found on all ports of the MTN, the method cannot guarantee a total, but a partial solution.

- Constraint of empty container transportation' costs: each empty container has to be transported with a cost calculated unit " $\mu$ " compared to the distance between the ports. This cost must be as minimal as possible for the owners of these containers.

- Distance constraint for a shipment of empty containers: The distance between each pair of ports should be the most optimal for ensuring a maximum gain to the company (the cost is proportional to the distance).

\subsection{Transfer process of full containers}

To arrive at a destination, full containers can pass through one or more ports of call if the source port of the client' demand is not directly connected to the destination (Fig. 6).

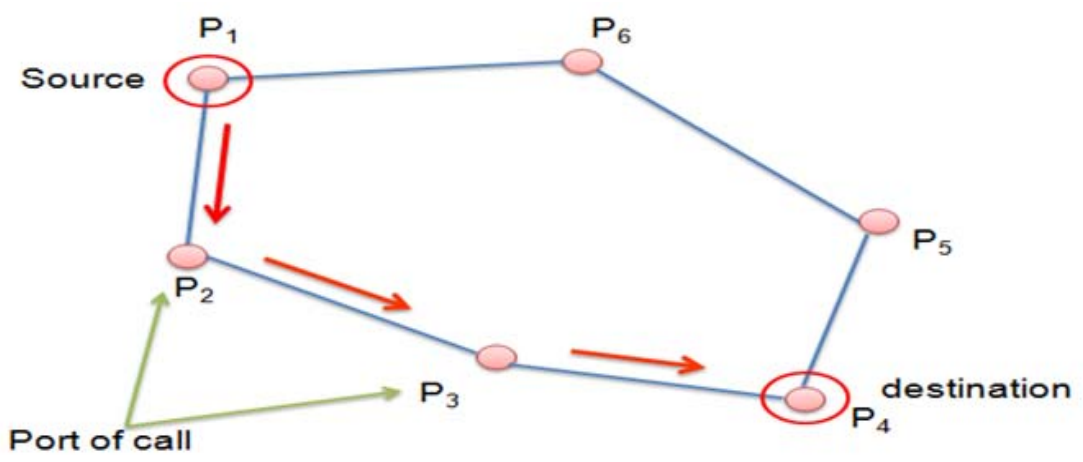

Figure 6. Transfer of full containers (source / destination)

Once the full containers arrive at the port of destination, they will be unloaded. The stock of empty containers at this port will be updated, and the processing of another client's demands in another port will be continued (Fig. 7). 


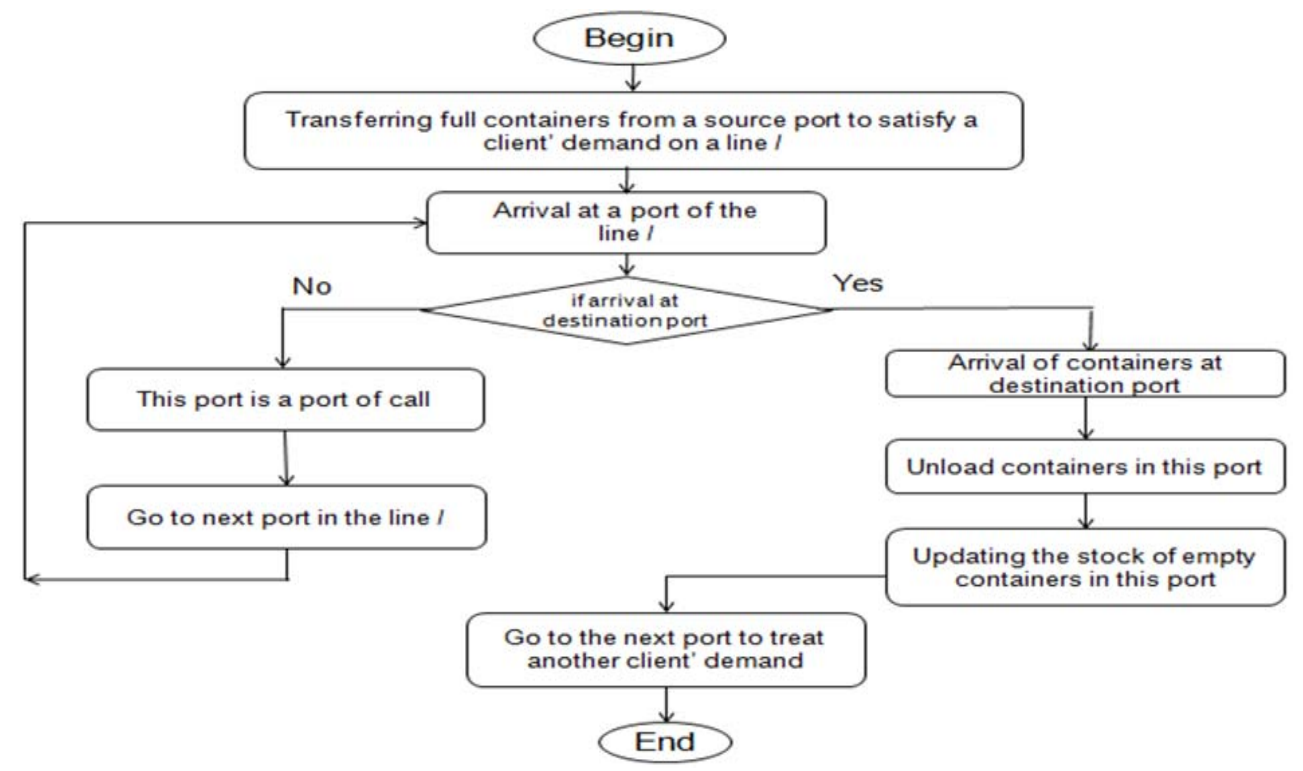

Figure 7. Transfer Process of full containers (source / destination)

\section{Illustrative Example}

In this section, the authors present an experiment that they have achieved on an example of MTN, which consists of six ports (Fig. 8) interconnected by 3 lines as follows:

- Line $1=\{(\mathrm{P} 1, \mathrm{P} 2),(\mathrm{P} 2, \mathrm{P} 3),(\mathrm{P} 3, \mathrm{P} 1)\}$

- Line $2=\{(\mathrm{P} 1, \mathrm{P} 4),(\mathrm{P} 4, \mathrm{P} 5),(\mathrm{P} 5, \mathrm{P} 1)\}$

- Line $3=\{(\mathrm{P} 5, \mathrm{P} 6),(\mathrm{P} 6, \mathrm{P} 2),(\mathrm{P} 2, \mathrm{P} 3),(\mathrm{P} 3, \mathrm{P} 5)\}$

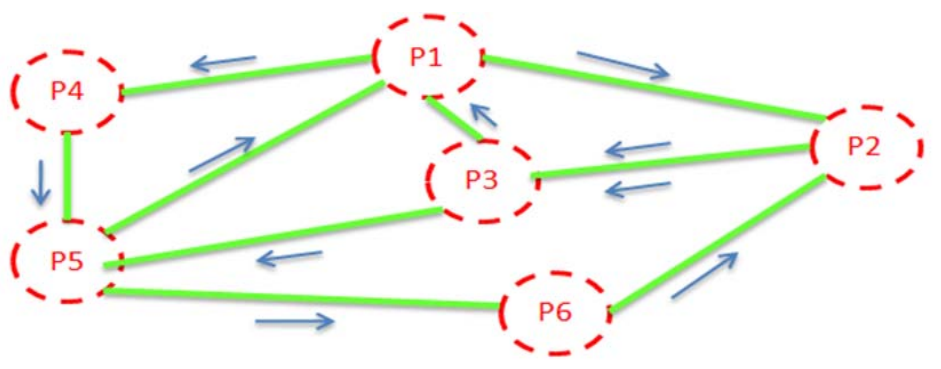

Figure 8. Maritime Transportation Network

On this network, the authors have achieved a number of scenarios by varying the number of client's demands and the total number of empty containers initially assigned to all the ports, as follows:

Scenario 1: Total number of empty containers 100, total number of client demands 20

Scenario 2: Total number of empty containers 200, total number of client demands 40

Scenario 3: Total number of empty containers 300, total number of client demands 60

Scenario 4: Total number of empty containers 400, total number of client demands 80

Scenario 5: Total number of empty containers 500, total number of client demands 100

Scenario 6: Total number of empty containers 700, total number of client demands 120

A set of empty containers is assigned to each port initially in the stock. After, the researchers start the clients' demands affectation. Each demand is indicated by a $\mathrm{N}^{\circ}$ of demand, a source port, destination port, a number of necessary empty containers, the line on which is assigned the demand, and an initial state "untreated".

Once treatment is started, each port processes its demands. The state of the demand, which is placed in the queue, is equal to "unprocessed". Once the demand will be processed, its status can take one of the two values "treated without TS" or "treated with TS.

If status = "treated without TS" in this case, the source port was able to meet demand with the number of empty containers that were available in its stock.

If status = "treated with TS" in this situation, the source port could not process the demand because the number of containers available in the stock is less than the demand. Therefore, the port has issued a 
demand for aid to ports in its neighbourhood in order to look for empty containers by applying the Taboo Search. To see the effectiveness of the present work in this case, the authors compared the TS method of searching empty containers with the random search method (without TS) in regards to the return' price of empty containers (cost with TS and cost without TS respectively, see Table 2).

Table 2. Extract of clients' demands processing (Scenario 6)

\begin{tabular}{|c|c|c|c|c|c|c|c|c|c|c|}
\hline $\begin{array}{l}\text { Clients' } \\
\text { demand }\end{array}$ & $\begin{array}{c}\text { Source } \\
\text { Port }\end{array}$ & $\begin{array}{c}\text { Destination } \\
\text { Port }\end{array}$ & n_exp & $\begin{array}{c}\text { Line } \\
n^{\circ}\end{array}$ & Stat & $\begin{array}{c}\text { retained } \\
\text { port with } \\
\text { TS } \\
\end{array}$ & nb_cont & $\begin{array}{c}\text { Cost } \\
\text { with } \\
\text { TS }(\mu) \\
\end{array}$ & $\begin{array}{c}\text { Cost } \\
\text { without } \\
\text { TS }(\mu) \\
\end{array}$ & $\begin{array}{c}\text { Client } \\
\text { Cost }(\mu)\end{array}$ \\
\hline $\begin{array}{c}\text { Demand } \\
n^{\circ} 1\end{array}$ & 1 & 5 & 19 & 2 & $\begin{array}{c}\text { Processed } \\
\text { without } \\
\text { TS } \\
\end{array}$ & / & 0 & 0 & 0 & 167694 \\
\hline $\begin{array}{l}\vdots \\
\vdots \\
\vdots\end{array}$ & $\begin{array}{l}\vdots \\
\vdots \\
\vdots\end{array}$ & $\begin{array}{l}\vdots \\
\vdots \\
\vdots\end{array}$ & $\begin{array}{l}\vdots \\
\vdots \\
\vdots\end{array}$ & $\vdots \vdots$ & $\begin{array}{l}\vdots \\
\vdots \\
\vdots\end{array}$ & : & $\begin{array}{l}\vdots \\
\vdots \\
\vdots\end{array}$ & $\vdots \vdots$ & $\vdots \vdots$ & $\begin{array}{l}\vdots \\
\vdots \\
\vdots\end{array}$ \\
\hline $\begin{array}{c}\text { Demand } \\
n^{\circ} 82\end{array}$ & 5 & 2 & 11 & 3 & $\begin{array}{c}\text { Processed } \\
\text { with TS }\end{array}$ & port 2 & 5 & 34850 & 45915 & 67683 \\
\hline $\begin{array}{l}\text { Demand } \\
\mathrm{n}^{\circ} 83\end{array}$ & 3 & 2 & 5 & 3 & $\begin{array}{c}\text { Processed } \\
\text { without } \\
\text { TS } \\
\end{array}$ & / & 0 & 0 & 0 & 59370 \\
\hline $\begin{array}{l}\vdots \\
\vdots \\
\vdots\end{array}$ & $\begin{array}{l}\vdots \\
\vdots \\
\vdots\end{array}$ & $\vdots$ & $\begin{array}{l}\vdots \\
\vdots \\
\vdots\end{array}$ & $\begin{array}{l}\vdots \\
\vdots \\
\vdots\end{array}$ & $\begin{array}{l}\vdots \\
\vdots \\
\vdots\end{array}$ & $\vdots$ & $\begin{array}{l}\vdots \\
\vdots \\
\vdots\end{array}$ & $\begin{array}{l}\vdots \\
\vdots \\
\vdots\end{array}$ & $\begin{array}{l}\vdots \\
\vdots \\
\vdots\end{array}$ & \\
\hline $\begin{array}{c}\text { Demand } \\
\mathrm{n}^{\circ} 94\end{array}$ & 5 & 3 & 11 & 3 & $\begin{array}{c}\text { Processed } \\
\text { with TS }\end{array}$ & port 2 & 11 & 76670 & 101013 & 134640 \\
\hline $\begin{array}{l}\text { Demand } \\
n^{\circ} 95\end{array}$ & 3 & 2 & 19 & 3 & $\begin{array}{c}\text { Processed } \\
\text { without } \\
\text { TS } \\
\end{array}$ & I & 0 & 0 & 0 & 225606 \\
\hline $\begin{array}{c}\text { Demand } \\
\mathrm{n}^{\circ} 96\end{array}$ & 3 & 2 & 22 & 1 & $\begin{array}{c}\text { Processed } \\
\text { without } \\
\text { TS } \\
\end{array}$ & / & 0 & 0 & 0 & 197736 \\
\hline $\begin{array}{c}\text { Demand } \\
\mathrm{n}^{\circ} 97\end{array}$ & 5 & 6 & 19 & 3 & $\begin{array}{c}\text { Processed } \\
\text { with TS } \\
\end{array}$ & port 2 & 19 & 132430 & 174477 & 520098 \\
\hline $\begin{array}{l}\vdots \\
\vdots \\
\vdots\end{array}$ & $\begin{array}{l}\vdots \\
\vdots \\
\vdots\end{array}$ & $\begin{array}{l}\vdots \\
\vdots \\
\vdots\end{array}$ & $\begin{array}{l}\vdots \\
\vdots \\
\vdots\end{array}$ & $\vdots \vdots$ & $\begin{array}{l}\vdots \\
\vdots \\
\vdots\end{array}$ & $\vdots$ & $\begin{array}{l}\vdots \\
\vdots \\
\vdots\end{array}$ & $\begin{array}{l}\vdots \\
\vdots \\
\vdots\end{array}$ & 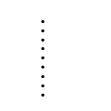 & $\begin{array}{l}\vdots \\
\vdots \\
\vdots\end{array}$ \\
\hline $\begin{array}{c}\text { Demand } \\
\mathrm{n}^{\circ} 111 \\
\end{array}$ & 1 & 5 & 14 & 2 & $\begin{array}{c}\text { Processed } \\
\text { with TS }\end{array}$ & port 4 & 3 & 11991 & 11991 & 123564 \\
\hline $\begin{array}{c}\text { Demand } \\
\mathrm{n}^{\circ} 112\end{array}$ & 2 & 1 & 8 & 1 & $\begin{array}{c}\text { Processed } \\
\text { without } \\
\text { TS } \\
\end{array}$ & I & 0 & 0 & 0 & 92360 \\
\hline $\begin{array}{c}\text { Demand } \\
n^{\circ} 113\end{array}$ & 2 & 5 & 17 & 3 & $\begin{array}{c}\text { Processed } \\
\text { without } \\
\text { TS }\end{array}$ & I & 0 & 0 & 0 & 200736 \\
\hline $\begin{array}{c}\text { Demand } \\
\mathrm{n}^{\circ} 114\end{array}$ & 5 & 3 & 8 & 3 & $\begin{array}{c}\text { Processed } \\
\text { with TS }\end{array}$ & port 2 & 8 & 55760 & 73464 & 97920 \\
\hline $\begin{array}{c}\text { Demand } \\
n^{\circ} 115\end{array}$ & 1 & 4 & 23 & 2 & $\begin{array}{c}\text { Processed } \\
\text { with TS }\end{array}$ & port 4 & 23 & 91931 & 91931 & 105225 \\
\hline $\begin{array}{c}\text { Demand } \\
\mathrm{n}^{\circ} 116\end{array}$ & 2 & 5 & 10 & 3 & $\begin{array}{c}\text { Processed } \\
\text { without } \\
\text { TS } \\
\end{array}$ & I & 0 & 0 & 0 & 118080 \\
\hline $\begin{array}{c}\text { Demand } \\
\mathrm{n}^{\circ} 117\end{array}$ & 5 & 2 & 11 & 3 & $\begin{array}{c}\text { Processed } \\
\text { with TS }\end{array}$ & port 2 & 11 & 76670 & 101013 & 67683 \\
\hline $\begin{array}{c}\text { Demand } \\
n^{\circ} 118\end{array}$ & 6 & 2 & 24 & 3 & $\begin{array}{c}\text { Processed } \\
\text { without } \\
\text { TS } \\
\end{array}$ & I & 0 & 0 & 0 & 81864 \\
\hline $\begin{array}{c}\text { Demand } \\
\mathrm{n}^{\circ} 119\end{array}$ & 1 & 4 & 16 & 2 & $\begin{array}{c}\text { Processed } \\
\text { with TS }\end{array}$ & port 4 & 16 & 63952 & 63952 & 73200 \\
\hline $\begin{array}{c}\text { Demand } \\
n^{\circ} 120\end{array}$ & 4 & 1 & 13 & 2 & $\begin{array}{c}\text { Processed } \\
\text { without } \\
\text { TS } \\
\end{array}$ & l & 0 & 0 & 0 & 139464 \\
\hline
\end{tabular}

For example, in Scenario 6, the demand $\mathrm{N}^{\circ} 82$ was presented at the source port P5. This demand needs 11 empty containers (

The authors of this article remark that the demand was treated with Taboo Search because the source port P5 needed 5 empty containers ( $\mathrm{nb}$ cont $=5)$, which were not available in its stock to meet this 
demand. They also note that Taboo Search allows to find the 5 missing empty containers at a less cost $34850 \mu$ (cost with TS) instead of $45915 \mu$ (cost without TS) if the source port chooses a neighbouring port in a random manner to look for the 5 empty containers. The researchers remark that the tool presented in this paper provides a gain for the owner of the containers concerning the cost of the empty containers' return on the MTN comparing the cost with TS $(34850 \mu)$ and cost without TS $(45915 \mu)$.

Finally, they have the cost $67683 \mu$ which represents the (client cost) that the client must pay to send his goods transported by 11 full containers from P5 to P2 on line 3.

Figure 9 allows to visualize the variation in the cost of transporting of empty containers. When a port cannot satisfy the demand, it is clear to see that the transport of empty containers with the application of the Taboo Search method is less expensive than the transport which is done without TS.

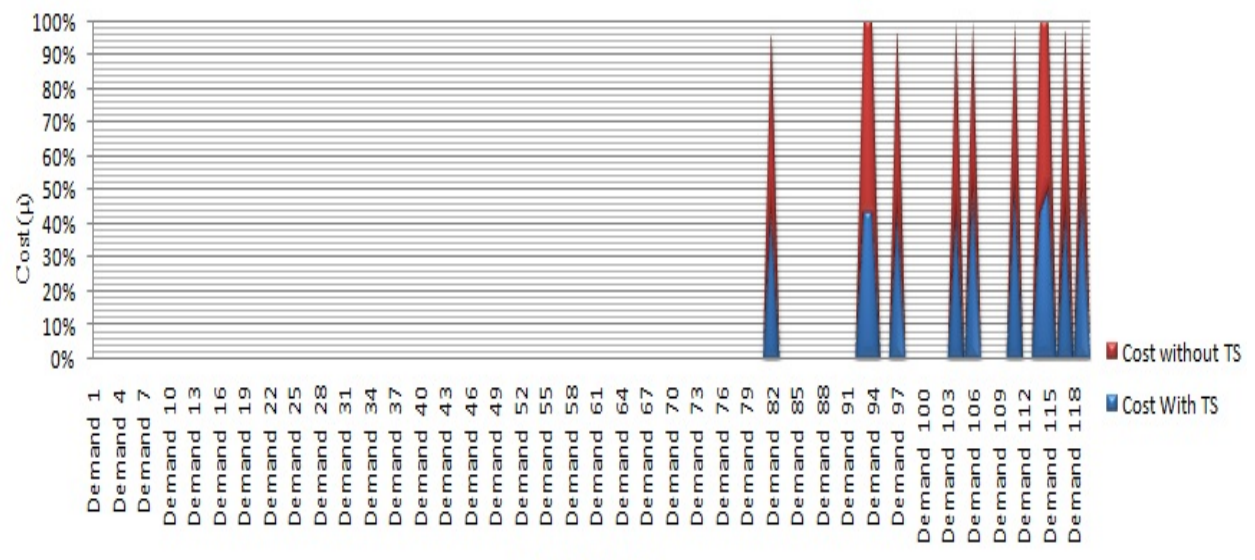

Clients' demands

Figure 9. Cost variation of empty containers' transportation with and without TS (Scenario 6)

Figure 10 shows the statistics obtained on the average cost of transporting empty containers on the network with and without Taboo Search for all scenarios studied by this proposal. These statistics are shown on a graph as curves (Fig. 11).

\begin{tabular}{|c|c|c|c|}
\hline Scenario & Nb clients' demands & Average cost with TS $(\boldsymbol{\mu})$ & Average cost without TS $(\boldsymbol{\mu})$ \\
\hline 1 & 20 & 7534,45 & 13432,2 \\
\hline 2 & 40 & 3890,22 & 7152,4 \\
\hline 3 & 60 & 10346,3 & 14390,35 \\
\hline 4 & 80 & 2525,07 & 6969,25 \\
\hline 5 & 100 & 902,91 & 1424,98 \\
\hline 6 & 120 & 6633,11 & 8255,98 \\
\hline
\end{tabular}

Figure 10. Average cost of empty containers' transportation with and without TS (all scenarios)

The authors notice that the cost of transporting empty containers through the Taboo Search is clearly much less expensive than the cost of transporting empty containers without it for all scenarios.

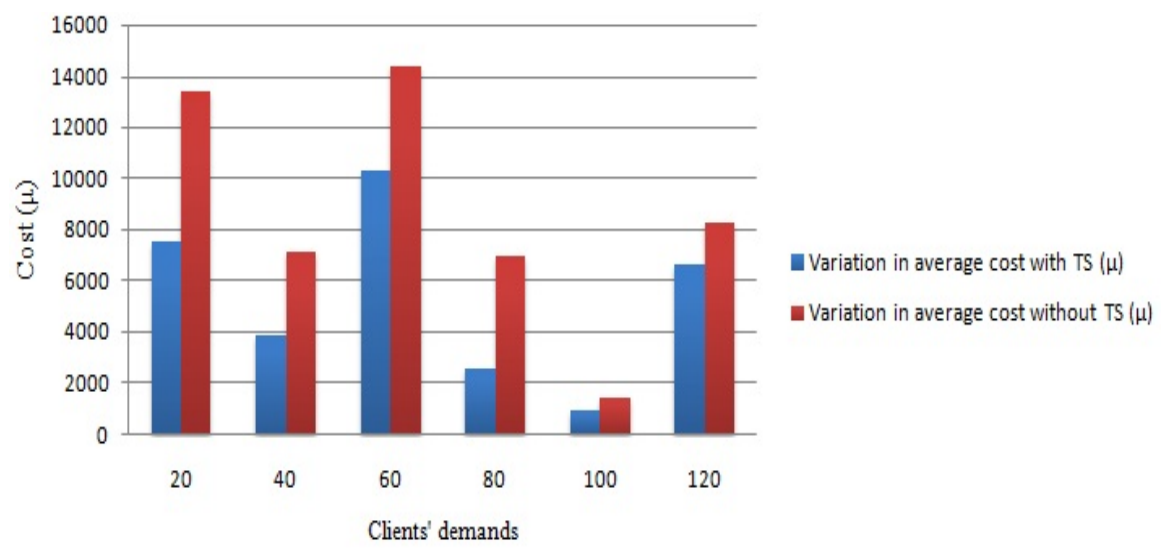

Figure 11. Variation in the average cost of empty containers' transportation with and without TS (all scenarios) 


\section{Synthesis}

Maritime Transport is the most useful mode of transport for international trade. Its expansion is very marked due to the flexibility of containerized transport, which keeps growing day after day within the globalised world. However, because of the imbalance in international trade activities, the container' owners meet a problem of empty containers that are unnecessarily accumulated in the import ports, despite the demand of a large number of these containers in export ports. This imbalance of the containers distribution is a result of the economic needs that differ from one country to another. The concern of the owners of the containers is how to manage and control the containers throughout the Maritime Transport Network and how ensure the return of empty containers cheaply.

For this purpose, the authors have proposed a comparative study (see Table 1) to see the participations and the solutions provided by other works of literature in the field of reverse logistics and the return of empty containers. The position of this contribution is related to what already existed. After the analysis of the Table 1, the authors noticed that the works cited in this paper, are interested in reverse logistics or the returns of empty containers in the MTN, but do not take into consideration the clients' demands and the return of containers (returned products) simultaneously. They target the problem of the return flow or the problem of direct logistical chain independently.

To better assist owners of containers in a MTN, this work allows to consider both: the client's demands and the return of the empty containers at a lower cost, because, if the transfer of full containers is on the charge of the client that sends his goods, the return of the empty containers is on the charge of the owner, that he must ensure the availability of the empty containers in each port of export.

\section{Conclusion and Future Prospects}

To conclude, the researchers can say that the Maritime Transport is becoming increasingly important and it represents a credible and attractive alternative to both land and air transport. Indeed, the different container transport' companies provide great efforts in order to identify opportunities to reduce costs associated with this transport and improve the quality of service. However, a major problem of container distribution imbalance is encountered by the container owners. As a result, this work's objective is to solve this problem.

The interest of the authors through this study is to satisfy the clients' demands to send their merchandises and assist the owners by facilitating the search for empty containers at lower costs. The contribution presented in this paper is used to represent the functioning of a MTN by optimizing the costs of the return of empty containers to meet the demands of the clients.

The proposed work is based on a heuristic method by neighbourhood. This latter is based on a representation of the MTN by a graph, which has enabled us to offer a help to the owners across an experimental study in the context of reverse logistics to identify and recover the empty containers. Subsequently, to achieve this goal, the authors have used Taboo Search method.

Encouraging results have been obtained that demonstrate the interest of the proposal. This work is far from over; why the researchers envision a consideration of several types of client's demands that differ from one season to another in order to make predictions about the distribution of containers. Besides, the authors propose to extend this contribution and take into consideration other parameters such as the costs of handling, storage, as well as an optimization of storage containers in ships and quays.

\section{References}

1. Alumur, S.A., Saldanha-da-Gama, F., Nickel, S. and Vedat, V. (2012) Multi-period reverse logistics network design. European Journal of Operational Research, 220(1), 67-78. DOI:10.1016/j.ejor.2011.12.045.

2. Belayachi, N., Gelareh, S. and Bouamrane K. (2015) Reverse logistics in the liner shipping industry. In: the 45th International Conference on Computers \& Industrial Engineering (CIE45), October 2015, Metz, France, ISBN: 978-1-5108-1745-6.

3. Crainic, T.G. (2000) Service network design in freight transportation. European Journal of Operational Research, 122 (2), 272-288. DOI: 10.1016/S0377-2217(99)00233-7.

4. Francesco, M.D., Lai, M. and Zuddas, P. (2013) Maritime repositioning of empty containers under uncertain port disruptions. Journal of Computers \& Industrial Engineering, 64(3), 827-837. DOI:10.1016/j.cie.2012.12.014. 
5. Gelareh, S., Nickel, S. and Pisinger, D. (2010) Liner shipping hub network design in a competitive environment. Transportation Research Part E, 46 (6), 991-1004. DOI: 10.1016/j.tre.2010.05.005.

6. Gelareh, S., Maculan, N., Mahey, P. and Monemi, R.N. (2013) Hub-and-spoke network design and fleet deployment for string planning of liner shipping. Applied Mathematical Modelling, 37(5), 3307-3321. DOI: 10.1016/j.apm.2012.07.017.

7. Gelareh, S. and Qiang, M. (2010) A novel modelling approach for the fleet deployment problem within a short-term planning horizon. Transportation Research Part E: Logistics and Transportation Review, 46 (1), 76-89. DOI: 10.1016/j.tre.2009.06.004.

8. Hu, T.L., Sheu, J.B. and Huang K.H. (2002) A reverse logistics cost minimization model for the treatment of hazardous wastes. International Journal of Transportation Research Part E, 38(6), 457473, DOI: 10.1016/S1366-5545(02)00020-0.

9. Lee, J.E., Gen, M. and Rhee, K.G. (2009) Network model and optimization of reverse logistics by hybrid genetic algorithm. Journal of Computers \& Industrial Engineering, 56(3), 951-964. DOI: 10.1016/j.cie.2008.09.021.

10. Meng, Q., Wang, S. and Liu, Z. (2012) Network design for shipping service of large-scale intermodal liners. Transportation Research Record, 2269(1), 42-50. DOI: 10.3141/2269-05.

11. Min, H., Ko, H.J. and Ko, C.S. (2006) A genetic algorithm approach to developing the multi-echelon reverse logistics network for product returns. International Journal of Management Science, 34 (1), 56 - 69. DOI: 10.1016/j.omega.2004.07.025.

12. Mutha, A. and Pokharel, S. (2009) Strategic network design for reverse logistics and remanufacturing using new and old product modules. Journal of Computers \& Industrial Engineering, 56 (1), 334346. DOI:10.1016/j.cie.2008.06.006.

13. Ramezani, M., Bashiri, M. and Tavakkoli-Moghaddam, R. (2013) A new multi-objective stochastic model for a forward/reverse logistic network design with responsiveness and quality level. Journal of Applied Mathematical Modelling, 37 (2), 328-344. DOI:10.1016/j.apm.2012.02.032

14. Shuaian, W., Meng, Q. and Sun, Z. (2013) Container routing in liner shipping. Transportation Research Part E, 49 (1), 1-7. DOI: 10.1016/j.tre.2012.06.009.

15. Song, D.P. and Dong, J.X. (2013) Long-haul liner service route design with ship deployment and empty container repositioning. Transportation Research Part B, 55(2013), 188-211. DOI:10.1016/j.trb.2013.06.012.

16. Srivastava, S.K. (2008) Network design for reverse logistics. The International Journal of Management Science, 36(4), 535-548. DOI:10.1016/j.omega.2006.11.012.

17. Zhou, Y. and Wang, S. (2008) Generic model of reverse logistics network design. Journal of Transportation Systems Engineering and Information Technology, 8(3), 71-78. DOI: 10.1016/S1570-6672(08)60025-2.

18. Yachba, K., Gelareh, S. and Bouamrane, K. (2016) Storage management of hazardous containers using the genetic algorithm. Transport and Telecommunication, 17(4), 371-383. DOI: 10.1515/ttj2016-0033. 